\title{
BREVES COMENTÁRIOS SOBRE A PROVA PERICIAL AMBIENTAL À LUZ DAS NOVAS REGRAS DO CÓDIGO DE PROCESSO CIVIL: PERÍCIA CONSENSUAL E SIMPLIFICADA
}

\author{
Daiana França Topan; Fabio Ferreira Morong \\ Universidade do Oeste Paulista - UNOESTE, Especialização em Perícia Forense, Presidente Prudente, SP. E-mail: \\ daianafrancatopan@hotmail.com; fabiomorong@hotmail.com
}

\begin{abstract}
RESUMO
As inovações trazidas pelo Novo Código de Processo Civil apontam avanços comuns referentes a todas modalidades periciais, especialmente em relação à agilidade, simplificação e cooperação entre as partes na produção da prova pericial. Este artigo realiza um estudo teórico-conceitual associando perícia ambiental junto as inovações advindas do referido Código, desenvolvendo os reflexos da perícia consensual e simplificada na esfera ambiental. Aplica-se o método dedutivo para sistematizar os dados coletados e consultas à legislação nacional e doutrinas relevantes no objeto de estudo. Conclui-se que o novo regulamento está pautado na celeridade, simplificação e efetividade em relação a produção da prova, porém, diante de situações complexas como as de caráter ambiental, tais medidas podem apresentar sérios riscos aos princípios de preservação e proteção ambiental. Portanto, é imprescindível que exista discernimento sobre a tutela ambiental diante do provimento da simplificação da perícia ambiental, pugnando por uma especial cautela nas decisões a fim de assegurar o meio ambiente equilibrado.
\end{abstract}

Palavras-chave: perícia ambiental, Novo Código de Processo Civil, Perícia simplificada, Perícia consensual, Legislação Ambiental.

\section{BRIEF COMMENTS ON THE ENVIRONMENTAL PROOF IN THE LIGHT OF THE NEW RULES OF THE CODE OF CIVIL PROCESS: CONSENSUAL AND SIMPLIFIED EXPERIENCE}

\section{ABSTRACT}

The innovations brought by the New Code of Civil Procedure show common advances relative all expert modalities, especially in relation to agility, simplification and cooperation between section in production of expert evidence. This article accomplish a theoreticalconceptual study associating environmental expertise with the innovations coming from Code, developing reflexes of the consensual and simplified expertise in the environmental sphere.The deductive method is used to systematize the collected data and consultations with the national legislation and relevant doctrines in the object of study. It is concluded that the new regulation is based on speed, simplification and effectiveness in relation to the production of evidence, however, faced with complex situations such as those of an environmental nature, such measures may present serious risks to the principles of preservation and environmental protection. Therefore, it is imperative that there be discernment about environmental stewardship by providing for the simplification of environmental expertise, with a special caution in decisions in order to ensure a balanced environment.

Keywords: environmental expertise, New Civil Procedure Code, simplified expertise, consensual expertise, Legislation.

\section{INTRODUÇÃO}

A concepção antiga do crescimento a qualquer preço não se impõe sobre a provocação de um modelo sustentável de desenvolvimento democrático, que é menos perturbador ao meio Colloquium Socialis, Presidente Prudente, v. 01, n. Especial 2, Jul/Dez, 2017, p.236-242. DOI: 10.5747/cs.2017.v01.nesp2.s0142 
ambiente. A utilização de recursos naturais não renováveis de forma absurda e descontrolada pelo homem gera uma catástrofe ambiental e provoca no direito ambiental, de modo geral uma acentuação nas penalidades no que diz respeito à proteção ambiental.

Pois bem, diante de tais problemáticas a proteção ambiental é, entre outras, assegurada também por instrumentos técnicos que podem contribuir com avaliação geral de impactos ambientais, bem como em sua mitigação e prevenção. Neste contexto, destaca-se a figura da perícia ambiental como ferramenta importante não apenas no papel de prevenção e proteção, como também no que se refere ao desenvolvimento sustentável.

Assim, as inovações trazidas pelo Novo Código de Processo Civil instituído pela Lei Federal $\mathrm{n}$ ⒔105/2015, de forma geral e com algumas imperfeições e críticas, implementam alguns avanços nos procedimentos comuns referentes a todas as modalidades periciais, especialmente no que concerne a agilidade, simplificação e cooperação entre as partes.

Logo, o presente trabalho objetiva realizar um estudo teórico-conceitual em relação à perícia ambiental ligada às inovações oriundas do Novo Código Processo Civil, destacando, porém, o enfoque da perícia consensual e simplificada, abordando seus aspectos positivos e negativos.

\section{METODOLOGIA}

O método utilizado será dedutivo, demonstrando a aplicação das diferentes teorias e princípios, e analisando as formas que o Direito está tutelando o meio ambiente.

\section{A CORRELAÇÃo GERAL ENTRE PERÍCIA AMBIENTAL E O NOVO CóDIGO DE PROCESSO CIVIL}

Não há dúvida que a Perícia Ambiental é um instrumento de extrema relevância na atualidade, uma vez que rapidez e dinâmica das alterações ocorridas na sociedade contemporânea ensejaram um complexo e rápido processo de transformações no meio ambiente em razão da ação do homem, causando de maneira acelerada e acentuada o desequilíbrio, a redução e também a extinção de espécies e ecossistemas (ALMEIDA; OLIVEIRA; PANNO, 2003).

A perícia ambiental é um meio de prova utilizado em processos judiciais, sujeito à mesma regulamentação prevista pelo Código de Processo Civil, com a mesma prática forense, mas que irá atender a demandas específicas advindas das questões ambientais, onde o principal objeto é o dano ambiental ocorrido, ou risco de sua ocorrência (SILVA, 2012).

Portanto, refere-se a uma atividade profissional de grande interesse técnico e social e de natureza complexa, cujo qual impõe ações multidisciplinares e a atuação de profissionais de grande qualificação para atuarem em questões ambientais, ademais de estudos e pesquisas que fundamentem o desenvolvimento de seus aspectos jurídicos, teóricos, técnicos e metodológicos (CORREIA, 2003).

Logo, é certo que a Perícia Ambiental está diretamente ligada à ação e atividade profissional de grande relevância técnica e social, de modo que exige-se em seu âmbito um verdadeiro conhecimento multidisciplinar e trabalho altamente especializado, haja vista que é sua imperiosidade é uma realidade cada vez mais crescente que desenvolve-se visando não só a evolução da legislação ambiental como também uma efetiva preservação e conservação do meio ambiente em todo seu conjunto.

Por sua vez, sua relação com o a norma processual civil é direta, senão vejamos. Segundo ALVES E MORONG (2016a, p. 02), a concepção do direito ambiental como um direito fundamental previsto na Constituição Federal gerou a necessidade de uma tutela efetiva para o meio ambiente, uma vez que o desenvolvimento da sociedade provocou um desequilíbrio ecológico. Assim, foram criadas normas protetivas ao meio ambiente em todo o globo terrestre, sendo que o Brasil possui uma das legislações mais completas na área ambiental. 
Os citados autores ainda descrevem que para alcançar resultados concretos na tutela do meio ambiente é imprescindível a instituição de um sistema processual moderno, que, todavia, não existe até então. Destarte, adotou-se a utilização de um microssistema processual ambiental, formado pela integração da Lei da Ação Civil Pública (Lei no 7.347/1985) e do Código de Defesa do Consumidor (Lei no 8.078/1990), aplicando-se subsidiariamente a estes o Código de Processo Civil (ALVES, MORONG, 2016a).

Ressalta-se que as ações civis públicas ambientais constituem o principal meio judicial utilizado para tutelar o equilíbrio ecológico, utilizando-se em seu processamento as técnicas processuais disciplinadas pelo microssistema processual ambiental, de maneira que a perícia ambiental enquadra-se neste contexto. MIRRA (2004), ao tratar dos meios de prova nas ações civis pública elucida de forma bem clara que o destaque inerente à perícia, diante das características das degradações ambientais, que dependem para sua exata apuração, em toda a sua extensão, seja com relação aos danos propriamente ditos, seja com relação ao nexo causal, seja com relação às providências reparatórias, de avaliações técnicas, com base científica, muitas vezes de grande complexidade. Daí por que se tem considerado a perícia como o meio de prova por excelência nas demandas ambientais.

Assim, como já mencionado acima, o Código de Processo Civil tem aplicação subsidiária a Ação Civil Pública, naquilo que não conflite com suas peculiaridades próprias, observando que em sede de interesses difusos tal fato deve ser regra e não exceção dada à importância na tutela ambiental. Logo, resta caracterizada a correlação entre a perícia ambiental, ação civil pública e o código de processo civil, o que justifica a importância do presente estudo.

\section{DA PERÍCIA CONSENSUAL E SIMPLIFICADA À LUZ DAS NOVAS REGRAS DO CÓDIGO DE PROCESSO CIVIL E A RELAÇAO INERENTE AO MEIO AMBIENTE}

A perícia está contemplada no novo Código de Processo Civil, que regulamenta os procedimentos comuns a todas as modalidades periciais, indistintamente, pelos artigos 464 a 480 . De proêmio é necessário salientar que de fato o Novo Código de Processo Civil trouxe inúmeros avanços sobre os procedimentos para a realização da prova pericial, buscando por maior celeridade processual, tratando prazos, honorários periciais, responsabilidade do perito e assistente técnico, grau de especialidade, entre outros importantes fatores.

Pois bem, o art. 464, caput e seu $\S 20$ do Novo Código de Processo Civil traz uma novidade ao permitir a substituição da prova pericial por "prova técnica simplificada" ou "perícia simplificada" quando o ponto controvertido for de menor complexidade. Esta prova define-a o $\S$ $3^{\circ}$, consiste na inquirição pelo juiz de especialista sobre ponto controvertido da causa que demande especial conhecimento científico ou técnico, cuja produção observará uma das variáveis do § 4․ (BUENO, 2017).

FERREIRA (2015) trata do tema como "Perícia Simplificada" e explica que se o ponto controvertido não contiver dificuldades tais que indiquem análises mais aprofundadas, pormenorizadas, que imponham trabalhos específicos, ou documentações, ou cálculos, enfim, tudo aquilo que indicasse que a confecção de um laudo pericial seria o mais adequado, concluirse-á ser uma perícia de menor complexidade, estando autorizada a oitiva do perito e de assistentes-técnicos em audiência.

Nesse diapasão, Marques (2015) esclarece que a prova pericial poderá ser substituída pela denominada "prova técnica simplificada" (CPC, art. 464), o que, contudo, não exclui, sobremaneira, a presença do perito, apenas altera a forma de sua atuação, simplificando o procedimento. Pois bem, nesta modalidade ainda que existam doutrinadores que defendem que não há novidades em razão de já haver previsão semelhante no Código de Processo Civil anterior (artigo 435), de fato, resta sim caracterizada uma inovação quando constata-se que os 
esclarecimentos orais (pessoais) do perito no antigo diploma possuíam natureza meramente complementar ao laudo pericial ou parecer apresentado, sendo então impossível substituir a prova pericial. De outro lado, a disposição atual prevê alcance muito mais abrangente que uma singela convocação de peritos ou assistentes técnicos para esclarecimentos complementares, haja vista que na ocasião de audiência o dispositivo legal ainda prevê a utilização de recursos tecnológicos voltados à adequada compreensão dos esclarecimentos dos experts (LEONEL, 2015).

Por sua vez, a Lei no 13.105/2015 traz não apenas a nomeação do perito pelo juiz como também concede que as partes em comum acordo possam escolher o perito para atuar no caso desde que as partes sejam plenamente capazes para utilizar esse recurso e a causa assuma autocomposição.

A pericia consensual não míngua a relevância do mister, substitui para todos os fins, a perícia que o perito nomeado pelo juiz formalizaria (ROSSI, 2016). Considerando as imposições realizadas nos incisos do caput do art. 471 do Código de Processo Civil de 2015, a chamada "perícia consensual", inovou ao consentir que as partes escolhessem o perito em comum acordo e, como descrito acima, o resultado obtido substitui a prova pericial que seria cumprida pelo perito nomeado pelo juiz. Essa atuação das partes na prática dos atos processuais com imensa cooperação proporciona a condução do processo de forma real pelos envolvidos e revela os verdadeiros interpretes da ação. Porém em nenhuma hipótese afasta ou renuncia o controle sobre a estabilidade da prática judicial, observando no inicio o requisito de capacidade das partes ao concernir sobre tema que tenha autocomposição (BUENO, 2017).

FERREIRA (2014), afirma que em algumas situações pode haver uma discussão nesse contexto, pois a figura do perito é de confiança (técnica e ética) do juiz que o designa, mas afirma que não se tornará um empecilho para o consenso entre as partes. Discorre ainda sobre a possibilidade, nessa situação de desconforto, de o juiz considerar a nomeação de perito-consultor para orientação crítico-consultiva, já que tem o dever-poder sobre essa designação e sua decisão necessita ser legítima.

MARTINS (2016), sustenta que a escolha do perito compartilhada pelas partes trará uma qualificação técnica maior e mais ajustada à lide em discussão. Expõe também que essa escolha em comum acordo pelas partes possa acelerar e simplificar a produção da prova, assegurando eficiência do sistema.

O artigo 471, $\S 1^{\circ}$ do Novo Código de Processo Civil preceitua que as partes prenunciam a escolha em consenso do expert e já anunciam os seus respectivos assistentes técnicos para acompanharem a efetivação da perícia, atualmente com data e local informados antecipadamente. Logo após, o juiz determinará prazo para exposição do laudo pericial e dos pareceres dos assistentes das partes (art 471,§ $2^{\circ}$ ) (MARTINS, 2016).

Nota-se que o profissional perito como árbitro terá uma competência técnica melhor e isso poderá diminuir eventuais decisões errôneas, considerando que a tutela do meio ambiente configura algo útil e otimista.

\section{DA CONTROVÉRSIA ENTRE AS INOVAÇÕES E PRINCÍPIOS AMBIENTAIS}

De fato, cumpre-se na perícia simplificada e até mesmo na consensual a simplificação, celeridade e menores custas processuais em situações de menor complexidade ambiental, haja vista que nestas situações as inovações possuem caráter positivo e menor complexidade, como por exemplo a situação de disposição irregular de entulhos de obras em terrenos baldios, realizada por carroceiros em cidades do interior, circunstancia típica de cidades pequenas (SOARES; OLIVEIRA; FIQUEIREDO).

Destarte, é certo que o novo Código de Processo Civil se fundamenta nos princípios da celeridade e efetividade processual, logo, orienta a confecção dos laudos e garante que os 
trabalhos técnicos alcancem suas finalidades de auxiliar o juiz na constituição de seu convencimento, sobretudo quando sejam exigidos conhecimentos técnicos ou científicos específicos e peculiares. Tal objetivo não está em desacordo com os princípios de prevenção e proteção ambiental, mas desde que estejam relacionados às questões simples e menos complexa, o que faz-se necessário salientar que na seara ambiental, as questões devem ser avaliadas com grande responsabilidade haja vista ser considerado um direito fundamental disposto na Carta Magna, onde estão previstas também as obrigações e deveres de preservação e proteção de forma geral.

Contudo, no que diz respeito às questões ambientais, é mesmo difícil não serem consideradas complexas, por menor intensidade que tenham dado seu amplo caráter de classificação, quais sejam meio ambiente natural, artificial, cultural e do trabalho (MORONG, 2014).

Por isso, é evidente que a perícia relacionada às questões ambientais, de maneira geral, é caracterizada por ser uma atividade profissional de natureza complexa e de relevante interesse social que cobra ações multidisciplinares e a participação de profissionais altamente qualificados para lidar com questões ambientais, além de estudos e pesquisas específicas que fundamentem o desenvolvimento de seus aspectos teóricos, técnicos, metodológicos e jurídicos, (CORREIA, 2003). Isso deixa claro que, segundo Peinado (2006) a perícia ambiental não está restrita apenas ao solo, mas também ao ar, entorno, enfim, a toda dinâmica que existe no território.

A perícia complexa, segundo Didier, Braga e Oliveira, (2015), é aquela que abrange mais de um conhecimento especializado (art. 475, CPC), cuja análise da coisa ou pessoa dependa de conhecimentos pertencentes a áreas diversas, requer uma certa multidisciplinariedade, como exatamente ocorre na grande maioria das lides de caráter ambiental pela sua própria natureza.

Assim, essa complexidade contrapõe-se claramente com o aspecto de celeridade e efetividade processual, uma vez que nestes casos a busca incessante de simplificação e agilidade coloca em dúvida uma boa solução questões técnicas, a exemplo da falta sem fundamento de uma Estudo de Impacto Ambiental e o Relatório de Impacto Ambiental. Soma-se a isso o fato de que possível erros, involuntários ou não, raramente serão controláveis ou reparáveis (FERREIRA, 2015), mesmo que em aparência tenha natureza menos complexa (se é que se pode considerar que uma questão ambiental não seja complexa em razão de sua própria classificação).

Com efeito, ainda que as novas regras busquem descomplicar, acelerar e diminuir os custos do processo, por sua vez também proporcionarão julgamentos e depreciações baseadas na restrição do contraditório e da expressividade do direito a prova. Assim, para que não decorra cerceamento infundado do consolidado contraditório em juízo, se faz necessário bom senso na escusa da realização da prova pericial justificado por pereceres técnicos formulados de forma judicial e extrajudicialmente, respeitando sempre os princípios ambientais (LEONEL, 2015).

Pode-se afirmar o mesmo no que tange a possibilidade de perícia consensual envolvendo questões ambientais. Basta raciocinar que não é difícil as partes poderem estabelecer uma espécie de acordo de procedimento, conforme regulamenta o art. 191 do novo Código, trazendo ao processo um projeto de sequência da instrução, inclusive com o nome do perito oficial escolhido de comum acordo entre os litigantes (RUBIN, 2015).

Ora, tal fato permite que o interesse privado se sobreponha ao interesse público e aos fundamentos ambientais, o que não é tolerável pela legislação brasileira, ademais de caracterizar um grande risco de ordem ambiental.

Deste modo, resta evidente que alterações inerentes à simplificação e ao consenso não são plenamente positivas ante a complexidade geral da pericial ambiental, de modo que, salvo exceção, poderão ser prejudiciais à preservação e proteção do meio ambiente, violando os princípios constitucionais da prevenção, precaução e proibição ao retrocesso. 


\section{CONCLUSÃO}

Constata-se que o novo regulamento é disciplinado pela agilidade e eficácia referente à elaboração da prova pericial quando certifica sua simplificação e escolha consensual do perito. Essas alterações não são de todo positivas perante a complexidade de uma prova pericial ambiental. Salvo exceção, resta evidente que poderão ser prejudiciais à preservação e proteção do meio ambiente.

No que tange à perícia consensual, observa-se que em casos de eventual interesse particular que se sobreponha aos fundamentos ambientais, é provável que o trabalho pericial não atenda os rígidos critérios éticos que regem questões ambientais, o que acarretará sério risco ao meio ambiente.

Essas evoluções para simplificar o processo em questões ambientais, que via de regra são de natureza grave e complexa, claramente violarão princípios constitucionais como os da prevenção, da precaução e do não retrocesso. É imprescindível que exista discernimento sobre a tutela ambiental diante do provimento da simplificação e consenso da perícia ambiental, pugnando por uma especial cautela das decisões em casos específicos, sempre objetivando a maior prevenção e proteção do meio ambiente.

\section{REFERÊNCIAS}

ALMEIDA, J.R.; OLIVEIRA, S.G.; PANNO, M. Perícia ambiental. Rio de Janeiro: Thex, 2003.

ALVES, L.N.; MORONG, F.F. A nova tutela de urgência nas ações civis públicas ambientais: um instrumento de efetivação da proteção ao meio ambiente. Colloquium Socialis, Presidente Prudente, v. 01, n. 1, p.01-04 jan/abr 2017ạ.

ALVES, L.N.; MORONG, F.F. Efeitos Do Termo De Ajustamento De Conduta Em Matéria Ambiental E Seus Reflexos Nas Esferas Cível E Administrativa. Colloquium Socialis, Presidente Prudente, v.01, n. Especial, p.587-592, jan/abr 2017b.

BUENO, C.B. Novo Código de Processo Civil anotado. 3. ed. São Paulo: Saraiva, 2017.

CORREIA, P. A. S. Perícias Ambientais. Disciplina - Teoria Ecológica e Análise Ambiental - Universidade Federal da Paraíba. Orientação: Prof. Roberto Sasi. 2003. João Pessoa - PB. 14 p

DIDIER JUNIOR, F.; BRAGA, PAULA SARNO; OLIVEIRA, Rafael Alexandria de. Curso de Direito Processual Civil. Teoria da Prova, Direito Probatório, Decisão, Precedente, Coisa Julgada e Tutela Provisória, 10a edição, vol. 4, Salvador: Editora JusPodivm, 2015.

FERREIRA, W. S. A prova pericial no novo código de processo civil. O Novo Código de Processo Civil, Revista do Advogado. AASP, São Paulo, XXXV, no 126, pp. 204-209, maio de 2015.

LEONEL, R. B. Anotações sobre a prova no novo CPC. In "O Novo Código de Processo Civil", Revista do Advogado. AASP, São Paulo, XXXV, no 126, p. 175-181, maio de 2015.

MARTINS, A. C. A prova pericial no projeto do CPC: uma leitura a partir da experiência da arbitragem e do direito anglo-saxão. In FREIRE, Alexandre Reis Siqueira et al. Novas tendências do processo civil: estudos sobre o projeto do Novo Código de Processo Civil. Salvador: JusPodium, 2014, p. 61-62. 8

MIRRA, A. L.V. Ação civil pública e a reparação do dano ao meio ambiente. 2ª ed. São Paulo: Editora Juarez de Oliveira, 2004, p. 266-268. 
MORONG, F. F.. El régimen jurídico de las licencias y autorizaciones ambientales en España y Brasil: análisis jurídico-ambiental derivado de los aspectos novedosos de la normativa general de la Unión Europea sobre prevención y control integrados de la contaminación. 1. ed. Salamanca: Ediciones Universidad de Salamanca, 2014. v. 1. 851p .

PEINADO, L.B. Pericia ambiental e o desafio da multidisciplinaridade. 2006. Disponível em: www. Pericias ambientais.com.br. Acesso em: 5 abr. 2011.

ROSSI, C. A. D. P. A prova pericial na Lei no 13.105/2015: Novo Código de Processo Civil. Revista Jus Navigandi, ISSN 1518-4862, Teresina, ano 21, n. 4699, 13 maio $2016 . \quad$ Disponível em: <https://jus.com.br/artigos/48217>. Acesso em: 28 jul. 2017.

SILVA, S.B. Perícia Ambiental: Definições, Danos e Crimes Ambientais. UNOPAR Cient., Ciênc.

RUBIN, Fernando. Anotações aos artigos 464 a 484. In MACEDO, Elaine Harzhein; MIGLIAVACCA, Carolina Mores, Novo Código Civil Anotado, Escola Superior de Advocacia, Porto Alegre/RS, pp. 363-369, 2015.

FERREIRA, W. S. A prova pericial no novo código de processo civil. O Novo Código de Processo Civil, Revista do Advogado. AASP, São Paulo, XXXV, no 126, pp. 204-209, maio de 2015.

SOARES, A.F.S.; OLIVEIRA, F.A.R.; FIQUEIREDO, H.L. A PERÍCIA AMBIENTAL NO NOVO CPC. In: Congresso Brasileiro de Gestão Ambiental, VII, 2016, Campina Grande. Anal V-051 Legislação Ambiental, Licenciamento e Estudos Ambientais, Avaliação de Impactos Ambientais, Certificação Ambiental, ISO 14001, Campina Grande: IBEAS - Instituto Brasileiro de Estudos Ambientais,2016. Disponível em: http://www.ibeas.org.br/congresso/Trabalhos2016/V-051.pdf 